\title{
Comprehensive large-scale investigation and assessment of trace metal in the coastal sediments of Bohai Sea
}

\author{
Hongjun $\mathrm{Li}^{\mathrm{a}, *}$, Xuelu Gao ${ }^{\mathrm{b}}$, Yanbin $\mathrm{Gu}^{\mathrm{a}}$, Ruirui Wang ${ }^{\mathrm{a}}$, Pengfei Xie ${ }^{\mathrm{a}}$, Miao Liang ${ }^{\mathrm{a}}$, Hongxia Ming ${ }^{\mathrm{a}}$, \\ Jie $\mathrm{Su}^{\mathrm{a}}$ \\ ${ }^{a}$ Key Laboratory for Ecological Environment in Coastal Areas (SOA), National Marine Environmental Monitoring Center, Dalian 116023, Chine \\ ${ }^{\mathrm{b}}$ Key Laboratory of Coastal Environmental Processes and Ecological Remediation, Yantai Institute of Coastal Zone Research, Chinese Academy of Sciences, Yantai \\ 264003, China
}

\section{A R T I C L E I N F O}

\section{Keywords:}

Bohai Sea

Heavy metal

Sediment

Environment assessment

\begin{abstract}
A B S T R A C T
The Bohai Sea is characterized as a semi-closed sea with limited water exchange ability, which has been regarded as one of the most contaminated regions in China and has attracted public attention over the past decades. In recent years, the rapid industrialization and urbanization around the coastal region has resulted in a severe pollution pressure in the Bohai Sea. Although efforts from official government and scientific experts have been made to protect and restore the marine ecosystem, satisfactory achievements were not gained. Moreover, partial coastal areas in the Bohai Sea seemingly remain heavily polluted. In this study, we focused on five coastal regions around the Bohai Sea to study the spatial distribution pattern of trace elements in the sediments and their ecological risk. A total of 108 sediment samples were analyzed to determine the contamination degree of trace elements $(\mathrm{Cu}, \mathrm{Cd}, \mathrm{As}, \mathrm{Pb}, \mathrm{Zn}, \mathrm{Cr}$, and $\mathrm{Hg})$. Contamination factor $(C F)$, pollution load index ( $P L I)$, geoaccumulation index $\left(I_{\text {geo }}\right)$, and potential ecological risk index $(P E R I)$ were utilized to assess the pollution extent of these metals. Spatial distribution patterns revealed that the sedimentary environments of coastal Bohai were in good condition, except Jinzhou Bay, according to the Marine Sediment Quality of China. The concentrations of $\mathrm{Hg}$ and $\mathrm{Cd}$ were considerably higher than the average upper crust value and presented high potential ecological risk and considerable potential ecological risk, respectively. The overall environment quality of the coastal Bohai Sea does not seem to pose an extremely serious threat in terms of metal pollution. Thus, the government should continue implementing pollution control programs in the Bohai Sea.
\end{abstract}

\section{Introduction}

The Bohai Sea is a semi-closed shallow marginal sea located in the northeast of China. Given its special geographical and oceanographic characteristics, the Bohai Sea is sensitive to the environmental impacts of human activities in the catchment and sea areas. The Bohai Sea is connected to the Yellow Sea and bounded by the Bohai Strait between the Laotieshan in the southern Liaodong Peninsula and in the northern Shandong Peninsula. The Bohai Sea is surrounded by the three provinces of Liaoning, Hebei, and Shandong, and one municipality of Tianjin. The Bohai Sea covers an area of approximately $77,000 \mathrm{~km}^{2}$, with an average depth of $18 \mathrm{~m}$. Three major bays form inside the Bohai Sea, namely, Liaodong Bay to the north, Bohai Bay to the west, and Laizhou Bay to the south. The surrounding area of the Bohai Sea experiences rapid economic development, accompanied by substantial amounts of land-based pollutants. The ecosystem health of the Bohai Sea has attracted attention in recent years due to intensive human activities along the coastline. The Bohai Sea suffers from rapid industrialization and urbanization of adjacent terrestrial areas and is considered one of the most contaminated coastal areas in China (Hu et al., 2013; Liang et al., 2004; Wang and Wang, 2007; Xu et al., 2016). The Bohai Sea was formerly a famous fishing ground with several fishery resources. High fishing intensity, environmental pollution and habitat degradation have resulted in the sharp fishery decline in recent years (Jin, 2004; Xu et al., 2010). An urgent concern is that the Bohai Sea will degrade into a dead sea if no effective protection action is implemented. Thus far, investigation and assessment of heavy metals covering the entire area of the Bohai Sea have been inadequate. Gao et al. (2014) conducted a comprehensive literature review of the pollution status of trace elements $(\mathrm{Cu}, \mathrm{Cd}, \mathrm{As}, \mathrm{Pb}, \mathrm{Zn}, \mathrm{Cr}, \mathrm{Hg}$, and $\mathrm{Ni}$ ) in the seawaters, sediments, and inhabitant organisms over the past decades in the Bohai Sea. The authors concluded that metal pollution is closely related to the fast economic growth of the local region and is high in the coastal areas. However, considerable work has concentrated on a few

\footnotetext{
* Corresponding author.

E-mail address: hjli@nmemc.org.cn (H. Li).
} 
local areas. Comprehensive large-scale coastal investigation is lacking, which makes comparison a difficult task.

Although heavy metals are naturally originated elements that exist throughout the earth's crust, anthropogenic metal pollution that accompanies rapid economic development has attracted global attention (Cheng, 2003; Furness, 2018; Pan and Wang, 2012). Heavy metals are regarded as trace elements because of their occurrence in trace concentrations in various matrices. However, these metals notoriously cause serious contaminations because of their toxicological, ubiquitous, persistent, and irreversible characteristics in the environment. Reported sources of anthropogenic heavy metal include industrial, agricultural and domestic effluents, and atmospheric sources (Förstner and Wittmann, 2012). Excessive amounts of metals are released to estuarine and coastal environments through land-based sources as a result of rapid urbanization along the coastlines (Feng et al., 2004; Qiao et al., 2013). Heavy metal residues in polluted habitats accumulate through the dietary pathways of marine organisms, which may threaten the health of human beings (Zhang et al., 2012). Previous studies indicated that the coastal ecosystems in China are now facing increasing metal pollution (Gao et al., 2014; Wang et al., 2013).

Although contaminants in the marine environment derive from various sources, the majority of contaminants adsorb to particulate phases and inhabit the sediment. Coastal sediment has been regarded as an important sink and repository for trace elements. In addition, metalcontaminated sediments are frequent, with metal concentrations several orders of magnitude greater than pre-industrial or background values. Moreover, sediments will release other contaminants when the local environment changes (Eggleton and Thomas, 2004). Therefore, an investigation of metal concentrations in the sediment is important to evaluate the health status of coastal ecosystems and understand the possible environmental risks caused by anthropogenic activities.

In this study, we chose a few representative sites as the study area and conducted a systematic risk assessment of heavy metals in the coastal sediments of the Bohai Sea. Hence, this study mainly aimed to (1) investigate the spatial distribution of trace elements and assess the current situation of trace metal pollution in the coastal sediment of the Bohai Sea, (2) assess the ecological risk of heavy metals in the sediment, and (3) identify the main controlling factors in the distribution of metal contaminants and possible sources of pollution.

\section{Materials and methods}

\subsection{Description of sample area}

A total of 108 sampling sites were distributed over the coastal area of the Bohai Sea. These sites were mainly from five regions, including Shuangtaizi Estuary (27 sites), Jinzhou Bay (12 sites), Luanhe Estuary (24 sites), Bohai Bay (20 sites) and Laizhou Bay (25 sites) (Fig. 1). Sampling sites were selected to cover the important estuarine and coastal areas of the Bohai Sea. Shuangtaizi Estuary is located in the northeast of Bohai Sea, is an outlet of three main rivers, including Daliao River, Shuangtaizi (Liao) River and Daling River. Jinzhou Bay, located in northwest of Liaodong Gulf, is a semi-closed shallow water area. Six rivers including Lianshan River, Wuli River, Lao River, Cishan River, Zhouliu River and Tashan River flow into Jinzhou Bay (Wang et al., 2010). It is famous as an old industrial base, and become one of the most polluted coastal area in China. Luanhekou Estuary is located on the northwest coast of the Bohai Sea with water depths $<20 \mathrm{~m}$. Freshwater and sediment discharges have decreased greatly since the 1980s due to large dams and reservoirs built along the Luanhe River (Liu et al., 2016). Bohai Bay is located in the west of the Bohai Sea, near the city of Tianjin. Bohai Bay is a typical semi-enclosed coastal area and has limited water exchange with the ocean. Large quantities of industrial and domestic wastewater discharges flow into Bohai Bay from rivers of Beijn-Tianjin. The western coast of Bohai Bay locates the Tianjin Ports, the 10th largest port in the cargo throughout in the world. Laizhou Bay is located in the southern part of Bohai Sea, accounting for up to $10 \%$ of the total area (Zhuang and Gao, 2014). It's a semi-closed shallow area with average water depth less than $10 \mathrm{~m}$. There are more than a dozen of rivers running into the Laizhou Bay, among which Yellow River, Xiaoqinghe River and Wei River are the most important.

\subsection{Sample collection}

Throughout the survey, a global positioning system (GPS) was used to locate all sampling sites. Surface sediment samples $(0-5 \mathrm{~cm})$ were collected using a grab sampler in August 2015. At each site, three surface sediments were collected and placed into dark-colored polyethylene bags and sealed. After sampling, the samples were transported to the laboratory and stored at $4^{\circ} \mathrm{C}$ for further analysis.

\subsection{Analytical methods}

All digestive processes were referred to China National Standards (GB 17378.5-2007). Sediment samples (20 g) for element analysis were oven-dried $\left(<60^{\circ} \mathrm{C}\right)$, and then ground to powder $(<63 \mu \mathrm{m})$. Briefly, the powered samples $(0.5 \mathrm{~g})$ were digested in $20 \mathrm{~mL}$ of a 5:4:1 guaranteed reagent $\mathrm{HNO}_{3}+\mathrm{HClO}_{4}+\mathrm{HF}$ on a heating plate for $10 \mathrm{~h}$ to dryness. Afterwards, the residue was extracted with $\mathrm{HNO}_{3}$ and diluted to volume. The total organic carbon (TOC) was measured with an elemental analyzer (Vario EL-III). The concentrations of the dissolved heavy metals were determined by inductively coupled plasma mass spectrometry (ICP-MS, Thermo $\mathrm{X}$ series) for $\mathrm{Cd}, \mathrm{Pb}, \mathrm{Zn}, \mathrm{Cu}$, and $\mathrm{Cr}$, whereas the contents of $\mathrm{Hg}$ and As were determined using an atomic fluorescence spectrometer (AFS-920). Grain size of the sediment samples was analyzed using a Mastersizer-2000 particle size analyzer (Malvern, UK). Prior to particle size analysis, the fresh subsamples were pretreated with $10 \% \mathrm{H}_{2} \mathrm{O}_{2}$ and $1 \mathrm{~mol} / \mathrm{L} \mathrm{HCl}$ for $24 \mathrm{~h}$ to remove organic matter and biogenic carbonate. The samples were divided into four fraction on the basis of particle size: clay $(<2 \mu \mathrm{M})$, silt $(2-40 \mu \mathrm{M})$, fine sand $(40-200 \mu \mathrm{M})$ and coarse sand $(>200 \mu \mathrm{M})$ (Ip et al., 2007). About $20 \mathrm{~g}$ sediment samples for element analysis were oven-dried $\left(<60^{\circ} \mathrm{C}\right)$, and then ground to powder $(<63 \mu \mathrm{m})$. About $0.1 \mathrm{~g}$ powered samples were totally digested in a $60-\mathrm{mL}$ Teflon vessel with a mixed solution of $\mathrm{HNO}_{3}$ and $\mathrm{HClO}_{4}$. The solution was diluted with deionized water and filtered quantitatively in a $25-\mathrm{mL}$ colorimetric tube. One blank was digested similarly for quality control.

\subsection{Quality assurance and quality control (QA/QC)}

The analytical data quality was guaranteed through the implementation of quality assurance and quality control, with method blanks and standard reference materials. Three replicates were conducted for the determination of the total content of the metals. All analyses were carried out in duplicate, and the results were expressed as the mean. The precision of the analytical procedures, expressed as the relative standard deviation (RSD), was $>5 \%$ for all tests. The quality of the analytical procedures was tested by the recovery measurements on the Chinese national geo-standard (GBW-07333 and GBW-07314). The results were consistent with the reference values, and the differences were within $10 \%$.

\subsection{Assessment of metal contamination}

In order to best characterize heavy metal pollution extent in the coastal sediments of Bohai Sea, different empirically derived sediment quality guidelines were applied in this study.

\subsubsection{Sediment quality guidelines}

Sediment quality guidelines (SQGs) is a simple standard for assessing the risk of metal pollute in an aquatic ecosystem. In this study, two 


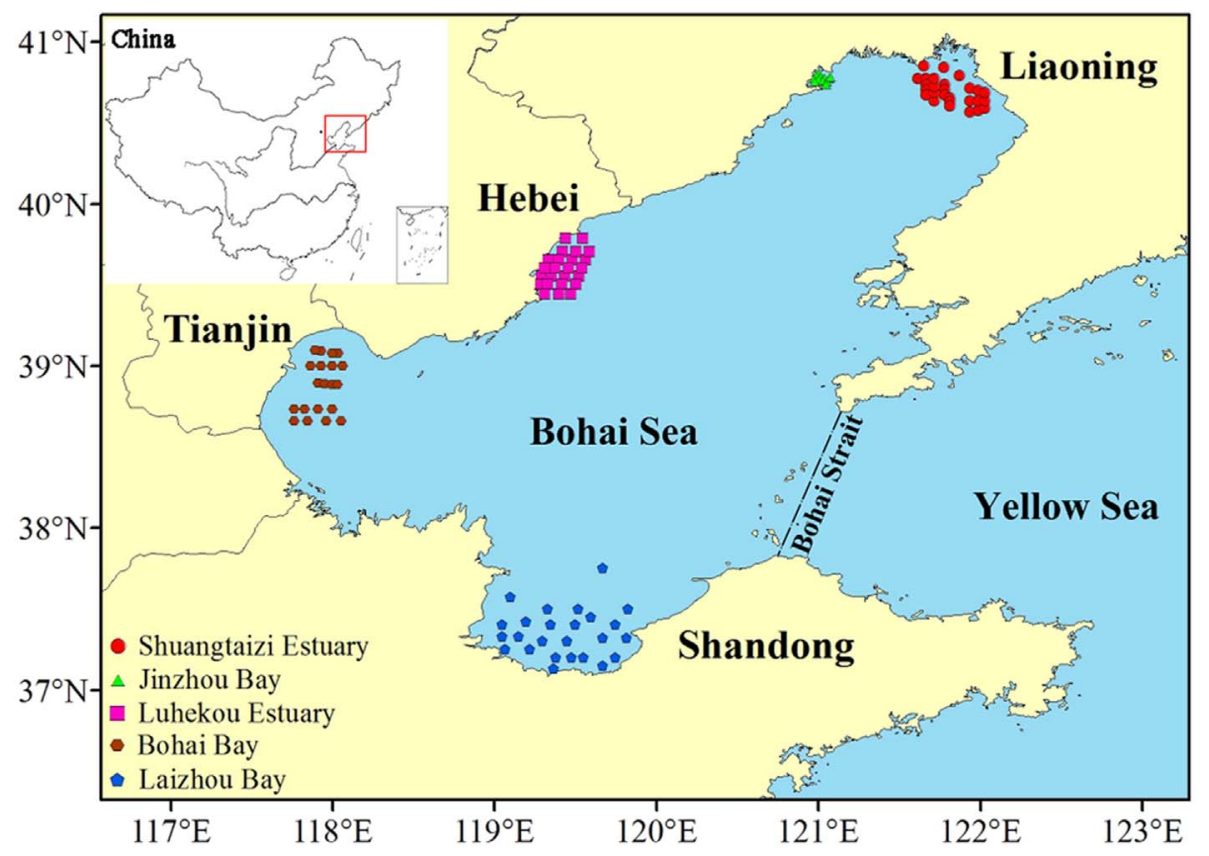

Fig. 1. Location map showing the sediment sample sites in the coastal Bohai Sea.

types of limit values, threshold effect concentration (TEC) and probable effect concentration (PEC), were applied to evaluate the potential risk of the ecosystem. The concentrations below the TEC represent a relatively safe degree, in which the adverse effects are not expected to occur. Concentrations between the TEC and the PEC represent a range where adverse effects occasionally occur. Concentrations above the PEC represent the adverse effects are expected to occur frequently (Long et al., 1998; Macdonald et al., 1996).

\subsubsection{The contamination factor}

The contamination factor $(C F)$ is a common analysis to evaluate the contamination of the environment by single substances in sediments, which was calculated as the ratio of the concentration of metals in sediment taken from sampling sites $\left(\mathrm{Me}_{\text {sample }}\right)$ to the pre-industrial reference value for the elements ( $\mathrm{Me}_{\text {baseline}}$ ). To describe the contamination of toxic substances in sediment, we may define a contamination factor accordingly:

$C F=\mathrm{Me}_{\text {sample }} / \mathrm{Me}_{\text {baseline }}$

The contamination factor is classified into four levels from low degree to high degree: low degree $(C F<1)$, moderate degree $(1 \leq C F<3)$, considerable degree $(3 \leq C F<6)$ and very high degree $(C F \geq 6)$ (Loska et al., 1997).

\subsubsection{The geo-accumulation index $\left(I_{\text {geo }}\right)$}

The geo-accumulation indexes introduced is another quantitative indicator that evaluates the pollution degree of single substances in sediment (Muller, 1969). This indicator is defined as follows:

$I_{\text {geo }}=\log _{2}\left(\frac{C_{n}}{1.5 B_{n}}\right)$

where $C_{n}$ is the concentration of the measured metal in the sample and $B_{n}$ is the geochemical background concentration of the metal (Gao et al., 1998). The factor of 1.5 is used as a "background matrix correction factor" to weaken the lithogenic effects. $I_{g e o}$ values are classified into seven levels (Table 1).

\subsubsection{Potential ecological risk index (PERI)}

The potential ecological risk index (PERI) was included to assess the comprehensive potential ecological risk of trace metals in sediment
Table 1

Description of sediment quality of $I_{g e o}$ classification.

\begin{tabular}{lll}
\hline$I_{\text {geo }}$ & Class & Quality of sediment \\
\hline$\leq 0$ & 0 & Unpolluted \\
$0-1$ & 1 & Unpolluted to moderately polluted \\
$1-2$ & 2 & Moderately polluted \\
$2-3$ & 3 & Moderately to strongly polluted \\
$3-4$ & 4 & Strongly polluted \\
$4-5$ & 5 & Strongly to extremely polluted \\
$>5$ & 6 & Extremely polluted \\
\hline
\end{tabular}

(Hakanson, 1980). This index assesses both the pollution status in sediment and environment effects with toxicology, which providing a better evaluation of the ecological risk of heavy metal contamination. The relevant equation is defined as follows:

$E_{R I}=\sum_{i}^{m} E_{r}^{i}=\sum_{i}^{m} T_{r}^{i} \cdot C_{f}^{i}$

where $C_{f}^{i}, T_{r}^{i}$ and $E_{r}^{i}$ represent the contamination factor of a given metal, the toxic-response factor of metal $i$, and the potential ecological risk coefficient, respectively. $T_{r}^{i}$ is the potential ecological risk factor of a single metal which was determined for $\mathrm{Zn}=1<\mathrm{Cr}=2<$ $\mathrm{Cu}=\mathrm{Pb}=5<\mathrm{As}=10<\mathrm{Cd}=30<\mathrm{Hg}=40$, and the $\mathrm{E}_{\mathrm{RI}}$ is the comprehensive potential ecological risk index of all the metals in sediments. The PERI of heavy metals was categorized according to five levels (Table 2).

\subsection{Multivariate statistical analysis}

Combined with the details of sediment circumstance and statistical analysis, considerable in-depth information, concerning the sources of metals could be obtained. Pearson's correlation matrix (CM) was applied to calculate correlation coefficients between the investigated variables. Based on the results of the correlation analysis, a principal component analysis (PCA) was used to identify tracers of heavy metal natural enrichment and anthropogenic influence in the studied area, which was calculated based on the correlation matrix. Before performing PCA, Kaiser-Meyer-Olkin (KMO) and Bartlett's sphericity tests 
Table 2

Risk grades indexes and grades of potential ecological risk of heavy metal pollution.

\begin{tabular}{|c|c|c|c|}
\hline$E_{r}^{i}$ & Risk grade & RI & Risk grade \\
\hline$<40$ & $\begin{array}{l}\text { Low potential ecological } \\
\text { risk }\end{array}$ & $<150$ & $\begin{array}{l}\text { Low potential ecological } \\
\text { risk }\end{array}$ \\
\hline $40-80$ & $\begin{array}{l}\text { Moderate potential } \\
\text { ecological risk }\end{array}$ & $150-300$ & $\begin{array}{l}\text { Moderate potential } \\
\text { ecological risk }\end{array}$ \\
\hline $80-160$ & $\begin{array}{l}\text { Considerable potential } \\
\text { ecological risk }\end{array}$ & $300-600$ & $\begin{array}{l}\text { High potential ecological } \\
\text { risk }\end{array}$ \\
\hline $160-320$ & $\begin{array}{l}\text { High potential ecological } \\
\text { risk }\end{array}$ & $\geq 600$ & $\begin{array}{l}\text { Significantly high potential } \\
\text { ecological risk }\end{array}$ \\
\hline$\geq 320$ & $\begin{array}{l}\text { Significantly high potential } \\
\text { ecological risk }\end{array}$ & & \\
\hline
\end{tabular}

were applied to examine the suitability of the data. The varimax rotation is used to obtain the varifactor, which represents the most meaningful information of the matrix in reduced dimensionality. Hierarchical cluster analysis (HCA), coupled with PCA, was used to confirm the results and group the variables. HCA was performed on the normalized data set using Ward's method with Euclidean distances as a measure of similarity based on AU/BP values (Ward, 1963). The PCA and HCA were performed in R 3.4.1 for Windows. The whole PCA processes were carried out with functions "KMO" and "cortest.bartlett" and "principal" from package "psych" (Revelle, 2017) for KMO, Bartlett's sphericity test, and principal component analysis respectively, and the cluster analysis was performed with function "hclust" in $\mathrm{R}$ package "stats".

\section{Results and discussion}

\subsection{Overall metal pollution in the coastal sediments of the Bohai Sea}

Table 3 summarizes the heavy metal concentrations ( $\mathrm{Hg}, \mathrm{As}, \mathrm{Zn}, \mathrm{Cd}$, $\mathrm{Pb}, \mathrm{Cu}$, and $\mathrm{Cr}$ ) in surface sediments collected from the coastal regions in the Bohai Sea, as well as the Marine Sediment Quality Standards and the background concentrations used in this study. The National Standard of China for GB 18668-2002 (SEPA, 2002), which was proposed by the State Oceanic Administration of China, is widely used to judge the potential risks of trace elements in marine sediments. This standard classifies marine sediment into three classes based on area function and target protection. Grade I criteria is applied to protect the habitats for marine organisms, including natural, rare, and endangered species, as well as the areas for human recreation and sports while Grade II is suitable for general industrial use and coastal tourism. The differences in metal concentrations in the sediment of Shuangtaizi Estuary, Jinzhou
Bay, Luanhekou Estuary, Bohai Bay, and Laizhou Bay were evident (Fig. 2). The highest average concentrations of $\mathrm{Hg}, \mathrm{As}, \mathrm{Zn}, \mathrm{Cd}, \mathrm{Pb}$, and $\mathrm{Cu}$ were distributed in Jinzhou Bay, where the highest value of $\mathrm{Cr}$ was found in Bohai Bay given that $\mathrm{Cr}$ concentration was unavailable in Jinzhou Bay in this study. According to Marine Sediment Quality (GB 18668-2002), the mean concentrations of all metals in the coastal sediments of the Bohai Sea were generally below the Grade I criteria, except for Jinzhou Bay. Clearly, the Jinzhou Bay was most seriously polluted, with the mean concentration of $\mathrm{Cd}$ being higher than the Grade II upper limit. The concentrations of $\mathrm{Hg}$ were higher than those in Grade I. This finding indicated that the sedimentary environments of coastal Bohai Sea (except Jinzhou Bay) were in good condition according to the Marine Sediment Quality of China.

Fig. 3 shows the distribution of the maximum level of metals in the coastal sediments of the Bohai Sea. The sediments in the Jinzhou Bay were the most seriously polluted, as evidenced by the highest value of $\mathrm{Cu}, \mathrm{Zn}, \mathrm{Hg}, \mathrm{Cd}, \mathrm{Pb}$, and As in the sample sites of Jinzhou Bay; the concentrations of $\mathrm{Zn}, \mathrm{Hg}$, Cd, and As were higher than those in the Marine Sediment Quality guidelines. The $\mathrm{Cr}$ value in the sediment was unavailable in Jinzhou Bay, and the maximum site was distributed in the Luanhe Estuary (Fig. 3). Gao et al. (2014) reviewed published papers on metal contamination in Bohai Sea over the past decades. They then summarized the concentrations of $\mathrm{As}, \mathrm{Cd}, \mathrm{Cu}, \mathrm{Hg}, \mathrm{Ni}, \mathrm{Pb}$, and $\mathrm{Zn}$ in sediments of Huludao, which is located near Jinzhou Bay (Gao et al., 2014). Compared with previous studies, the maximum level of metal concentrations did not exhibit a substantial change and even somewhat declined in the current study, which suggested that the pollution control program may be effective in diminishing the metal contamination of the Bohai Sea.

The metal concentrations were contrasted with the consensus-based TEC and PEC values (Table 4). The concentrations of Cd and $\mathrm{Zn}$ above PEC accounted for $1.9 \%$ and $2.8 \%$ of the samples, respectively, thereby suggesting that $\mathrm{Cd}$ and $\mathrm{Zn}$ tended to exhibit probable adverse biological effects. Furthermore, we identified samples between TEC-PEC for each element, with the percentage of $\mathrm{Cu}, \mathrm{Cr}$, and As accounting for $37.0 \%$, $33.3 \%$, and $30.2 \%$, respectively, thereby indicating that these metals occasionally showed biological effects.

The contamination factors of surface sediments in the study area were calculated, showing a sequence of $\mathrm{Hg}>\mathrm{Cd}>\mathrm{As}>\mathrm{Pb}>$ $\mathrm{Zn}>\mathrm{Cu}>\mathrm{Cr}$. Collectively, the average contamination factor of $\mathrm{Hg}$ $(5.8 \pm 9.0)$ and $\mathrm{Cd}(4.6 \pm 10.9)$ was classified into high degree, with As $(1.5 \pm 1.0), \mathrm{Pb}(1.15 \pm 0.59), \mathrm{Zn}(1.03 \pm 1.43)$ being moderate degree, and $\mathrm{Cu}(0.68 \pm 0.42)$ and $\mathrm{Cr}(0.48 \pm 0.16)$ being low degree. The $I_{\text {geo }}$ values of the coastal sediments in the Bohai Sea were -2.83 to 4.57 (average $0.76 \pm 1.75$ ) for $\mathrm{Hg},-2.28$ to 1.55 (average

Table 3

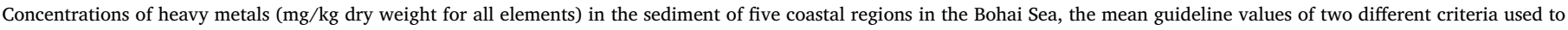
distinguish marine sediment quality and the average upper continental crust (UCC) values.

\begin{tabular}{|c|c|c|c|c|c|c|c|c|}
\hline Locations & $\mathrm{Cu}$ & $\mathrm{Zn}$ & $\mathrm{Cr}$ & $\mathrm{Hg}$ & $\mathrm{Cd}$ & $\mathrm{Pb}$ & As & References \\
\hline \multirow[t]{2}{*}{ Shuangtaizi Estuary } & $0.24-11.45$ & $12.6-26.4$ & $21.4-32.9$ & $0.004-0.021$ & $0.07-0.34$ & $7.45-17.3$ & $1.73-6.71$ & This study \\
\hline & 9.77 & 16.9 & 26.8 & 0.011 & 0.15 & 11.9 & 3.53 & \\
\hline \multirow[t]{2}{*}{ Jinzhou Bay } & $15.34-32.73$ & $109.54-599.26$ & nd & $0.118-0.335$ & $0.24-6.95$ & $20.79-54.03$ & $15.20-26.60$ & This study \\
\hline & 32.7 & 257.7 & & 0.225 & 2.48 & 32.5 & 19.9 & \\
\hline \multirow[t]{2}{*}{ Luanhekou Estuary } & $3.01-19.86$ & $20.41-46.28$ & $18.0-74.6$ & $0.015-0.025$ & $0.03-0.48$ & $4.54-17.72$ & $5.12-13.90$ & This study \\
\hline & 12.61 & 31.81 & 51.8 & 0.020 & 0.21 & 10.9 & 7.55 & \\
\hline \multirow[t]{2}{*}{ Bohai Bay } & $23.00-31.00$ & $56.7-83.4$ & $39.0-72.6$ & $0.002-0.031$ & $0.097-0.190$ & $18.8-28.4$ & $4.36-7.08$ & This study \\
\hline & 27.61 & 68.7 & 58.8 & 0.019 & 0.14 & 23.0 & 5.73 & \\
\hline \multirow[t]{2}{*}{ Laizhou Bay } & $4.94-27.60$ & $22.0-64.3$ & $19.3-52.4$ & $0.005-0.332$ & $0.09-0.42$ & $6.11-31.60$ & $4.44-24.60$ & This study \\
\hline & 19.2 & 45.2 & 40.4 & 0.084 & 0.16 & 17.35 & 11.07 & \\
\hline Grade I & 35 & 150 & 80 & 0.2 & 0.5 & 60 & 20 & SEPA (2002) \\
\hline Grade II & 100 & 350 & 150 & 0.5 & 1.5 & 130 & 65 & SEPA (2002) \\
\hline Average upper crust of East China & 27 & 66 & 99 & 0.0094 & 0.091 & 15 & 5.6 & Gao et al. (1998) \\
\hline
\end{tabular}

nd: no data.

Grade I: National Standard of China for Marine Sediment Quality GB 18668-2002 Grade I.

Grade II: National Standard of China for Marine Sediment Quality GB 18668-2002 Grade II. 

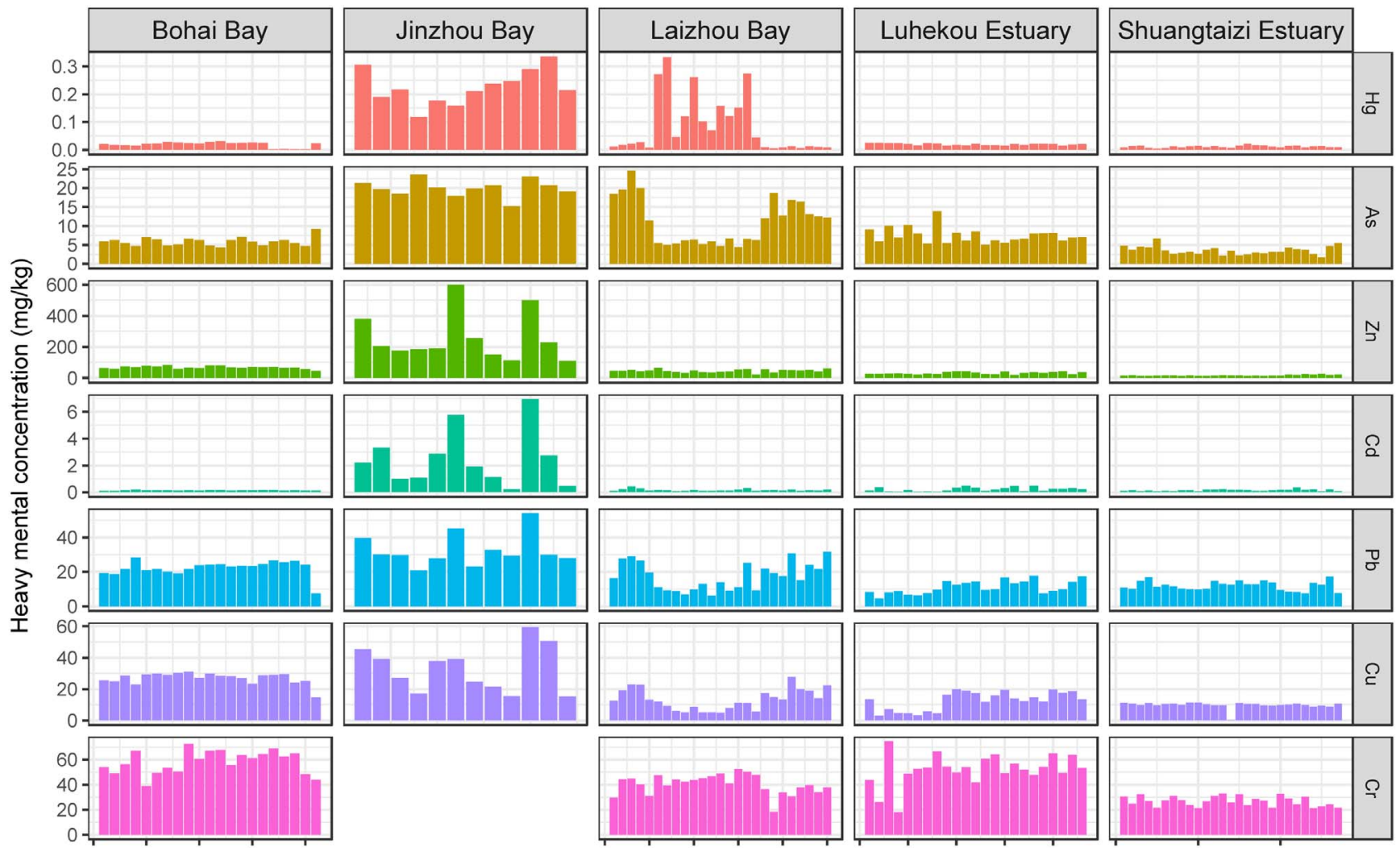

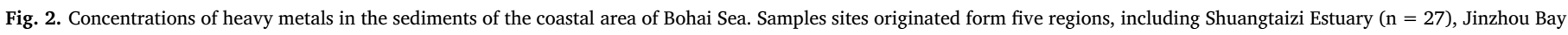
$(\mathrm{n}=12)$, Luanhe Estuary $(\mathrm{n}=24)$, Bohai Bay $(\mathrm{n}=20)$ and Laizhou Bay $(\mathrm{n}=25)$.

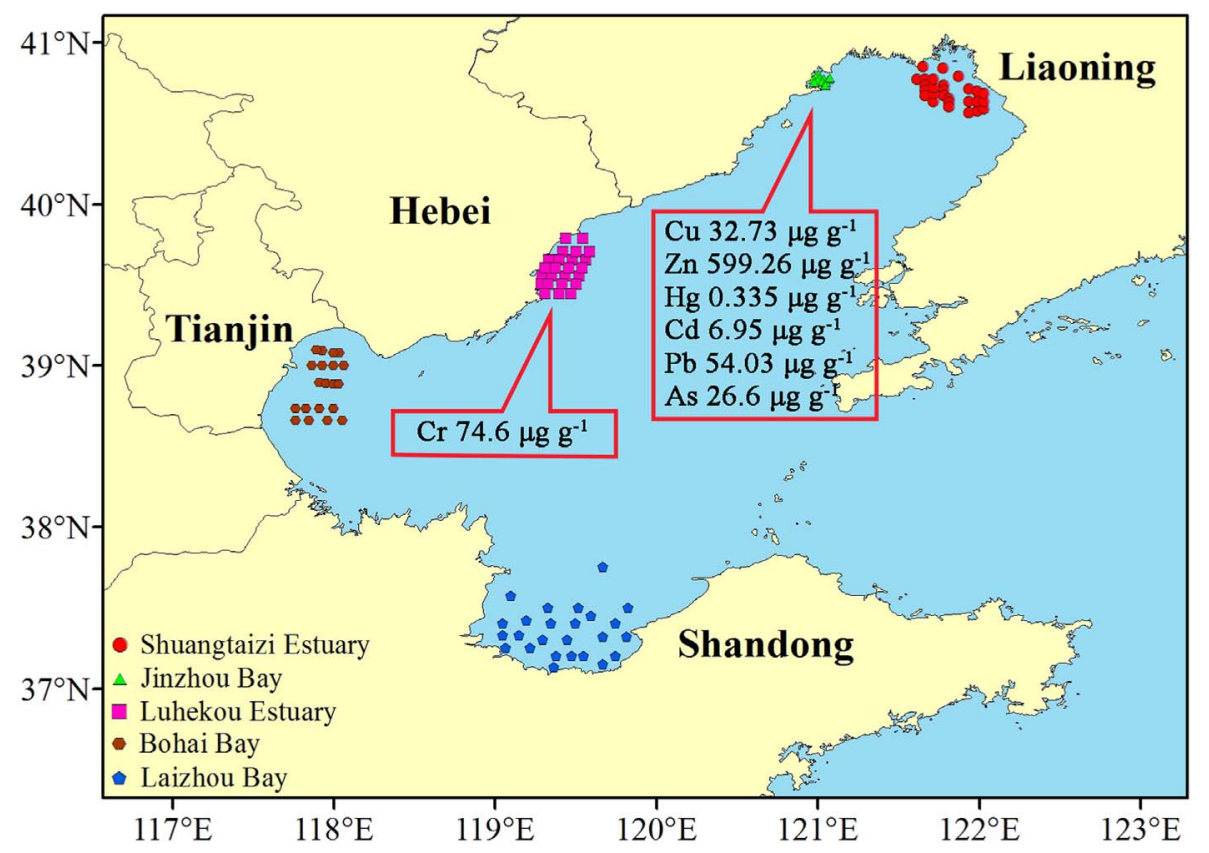

Fig. 3. Map of distribution of the maximum level of metals in the coastal sediment of Bohai Sea.

$-0.30 \pm 0.91$ ) for As, -2.86 to 2.71 (average $-1.14 \pm 1.18$ ) for $\mathrm{Zn}$, -2.23 to 5.67 (average $0.45 \pm 1.43$ ) for $\mathrm{Cd},-2.31$ to 1.26 (average $-0.56 \pm 0.72$ ) for $\mathrm{Pb},-7.29$ to 0.66 (average $-1.43 \pm 1.05$ ) for $\mathrm{Cu}$, -2.91 to -0.86 (average $-1.73 \pm 0.53$ ) for Cr. The average pollution degree of these metals decreased in the following order: $\mathrm{Hg}>\mathrm{Cd}>\mathrm{As}>\mathrm{Pb}>\mathrm{Zn}>\mathrm{Cu}>\mathrm{Cr}$, which is similar to that observed from the contamination factor values. $\mathrm{Hg}$ and $\mathrm{Cd}$ were the most common contaminants in the study areas. All the five regions were polluted by the two heavy metals. According to $I_{g e o}$ classification, the $I_{\text {geo }}$ values indicate no pollution of the investigated metals in the study area as a whole. Nonetheless, a certain deviation is observed, depending on each metal and sampling sites. The individual potential risk of the average $E_{r}^{i}$ for metals was $\mathrm{Hg}>\mathrm{Cd}>\mathrm{As}>\mathrm{Pb}$ $>\mathrm{Cu}>\mathrm{Zn}>\mathrm{Cr}$ (Fig. 4). Among the seven heavy metals, $\mathrm{Hg}$ and $\mathrm{Cd}$ presented high potential ecological risk and considerable potential ecological risk, respectively, as a result of their high toxicity factor. 
Table 4

Comparison of heavy metal concentrations $(\mu \mathrm{g} / \mathrm{g}$ ) of all samples in the coastal sediments of Bohai Sea with TEC and PEC.

\begin{tabular}{|c|c|c|c|c|c|c|c|}
\hline & Cd & $\mathrm{Cr}$ & $\mathrm{Cu}$ & $\mathrm{Pb}$ & $\mathrm{Zn}$ & $\mathrm{Hg}$ & As \\
\hline$\%$ of samples $<$ TEC & 90.7 & 69.8 & 63.0 & 94.4 & 90.7 & 84.3 & 66.7 \\
\hline$\%$ of samples between TEC-PEC & 7.4 & 30.2 & 37.0 & 5.6 & 6.5 & 15.7 & 33.3 \\
\hline$\%$ of samples $>$ PEC & 1.9 & 0 & 0 & 0 & 2.8 & 0 & 0 \\
\hline
\end{tabular}

TEC: threshold effect concentration;

PEC: probable effect concentration.

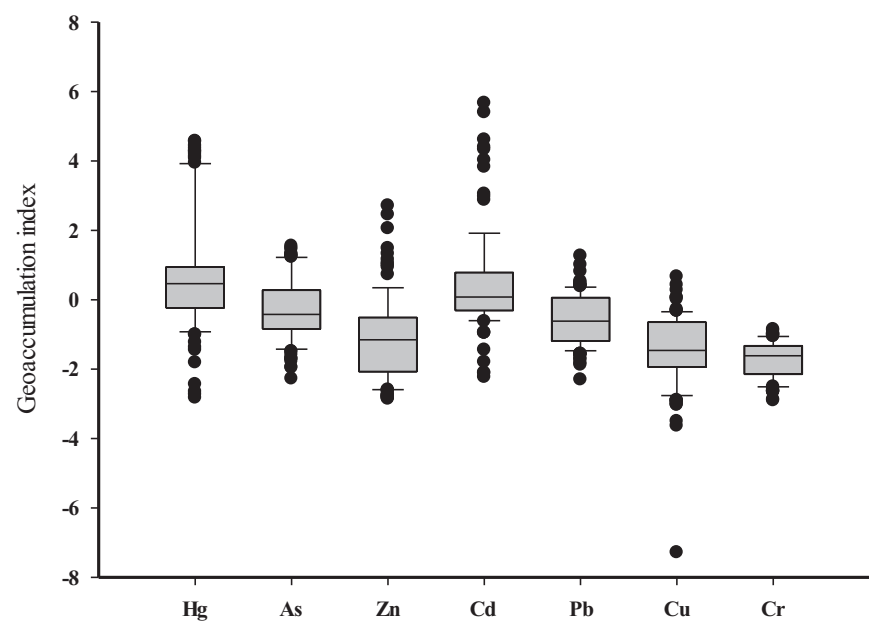

Fig. 4. Box-and-whisker plots for geoaccumulation indexes $\left(I_{\text {geo }}\right)$ of heavy metals in the coastal sediments of Bohai Sea.

To obtain an overview of the interrelationship among heavy metals and identify the possible sources in the Bohai Sea, multivariate statistical analyses (CM, PCA, and HCA) were performed. Pearson's CM was applied to measure the degree of correlations among the heavy metals and provide insight information regarding possible metal sources and pathways (Table 5). PCA was performed on heavy metals (Hg, As, Zn, $\mathrm{Cd}, \mathrm{Pb}, \mathrm{Cu}$, and $\mathrm{Cr}$ ), grain size parameters (Md), and TOC concentrations with varimax rotation. KMO and Bartlett's results were 0.82 and 1089.964 ( $\mathrm{df}=36, P<0.01$ ), respectively, indicating that PCA may be useful in dimensionality reductions. A component matrix of higher than 0.71 is generally considered a strong contributor, which is $<0.31$ as a weak contributor. Two main components with eigenvalues higher than 1 were determined, explaining $100 \%$ of the total variance (Table 6). The latter indicated that the original dataset can be represented by two new variables of principal components (PCs) (Fig. 5). The results indicated the different sources or controlling factors for the metals in the coastal sediments of the Bohai Sea.

The first group PC1 accounted for 52\% of the total variance. Cd, As, $\mathrm{Hg}$, and $\mathrm{Md}$ contributed strong positive loadings, whereas $\mathrm{Pd}$ and $\mathrm{Cr}$ had moderate negative loadings, $\mathrm{Cu}$ and $\mathrm{Zn}$ had weak positive and negative loadings, and TOC had strong negative loadings. The high loading of $\mathrm{Mz}$ highlighted the influence of fine-grained minerals on the distribution of heavy metals in the coastal sediments of the Bohai Sea. This finding indicated that $\mathrm{Cd}$, As, and $\mathrm{Hg}$ mainly came from a terrestrial source, especially via rivers. Combined with the results of $C F, I_{\text {geo }}$, and PERI, Cd, As, and $\mathrm{Hg}$ originated from terrestrial inputs, and PC1 could be ascribed as an anthropogenic factor. The second group PC2 accounted for $48 \%$ of the total variance. $\mathrm{Cu}, \mathrm{Zn}, \mathrm{Pb}$, and $\mathrm{Cr}$ contributed strong positive loadings. The concentrations of these four metals were slightly low or close to the background value. In addition, the results of $C F, I_{g e o}$, and PERI indicated that the contents of these three metals presented a low potential ecological risk. Thus, this group of metals might originate from natural resources, such as atmosphere precipitation and mineral weathering. In the current study, TOC has weak correlations with all the metals and Md, indicating that TOC may be from different sources or pathways. Therefore, the first group (As, Cd, and $\mathrm{Hg}$ ), second group $(\mathrm{Pb}, \mathrm{Cr}, \mathrm{Zn}$, and $\mathrm{Cu})$, and TOC may be from different sources. Moreover, Md may be an appropriate index to indicate As, $\mathrm{Cd}$, and $\mathrm{Hg}$ because of their strong positive correlations.

In this study, hierarchical clustering analysis was applied on the same dataset as PCA to understand the similarities among them using Ward's method. A dendrogram with single linkage Euclidean distances is shown in Fig. 6 . The distance axis represents the degree of association between groups of variables, that is, a low value on the axis corresponds to high significance of the association. In this dendrogram, all nine parameters are grouped into three statistically significant clusters. Cluster 1 consists of $\mathrm{Hg}, \mathrm{Cd}$, As, and $\mathrm{Md}$, whereas Cluster 2 consists of $\mathrm{Cu}, \mathrm{Pb}, \mathrm{Zn}$, and $\mathrm{Cr}$. Cluster 3 consists of TOC only, which further shows that the TOC has a weak association with other metals and Md. The dendrogram of HCA analysis confirmed the results of PCA.

\subsection{Situation of Jinzhou Bay}

Surrounded by one of the old industrial bases in China, Jinzhou Bay is well known for its metal pollution problem. China is the largest zinc (Zn) producer in the world. Notably, the largest zinc smelting plant in Asia is located in Huludao City along the coast of Jinzhou Bay. The serious contamination of metals in the sediments of Jinzhou Bay and its connected rivers is drawing increasing attention from the government and researchers nationwide (Fan et al., 2008; Li et al., 2012; Wang et al., 2010; Zheng et al., 2008). Zheng et al. (2008) found that Hg was the major toxicity contributor in Wuli River and Lianshan River, accounting for $53.3 \%-93.2 \%$ and $7.9 \%-54.9 \%$ of total toxicity, respectively, followed by Cd. Moreover, $\mathrm{Cd}$ is the major sediment toxicity contributor, accounting for $63.2 \%-66.9 \%$ of the total toxicity. In the current study, the sediments in the Jinzhou Bay were the most seriously polluted in the Bohai Sea on the basis of the map of the highest metal value. The mean values of $I_{\text {geo }}$ for $\mathrm{Hg}$ and $\mathrm{Cd}\left(I_{\text {geo }}=3.94\right.$ and 3.64, respectively) were classified into the heavily polluted level, indicating that Jinzhou Bay was suffering from these two elements. The extremely contaminated sediments are probably due to many years of random dumping of hazardous waste and free discharge of effluents by industries, such as the Huludao zinc plant, the Jinxi oil refinery, Jinhua chemical engineering, Huludao's massive shipyard, and several arms factories. Lu et al. (2010) found that dust precipitation from the Huludao zinc plant was the primary source of $\mathrm{Cd}, \mathrm{Pb}$, and $\mathrm{Zn}$ pollutants. The average deposition rates of $\mathrm{Cd}, \mathrm{Pb}$, and $\mathrm{Zn}$ were $0.33,1.75$, and $30.97 \mathrm{~g} / \mathrm{m}^{2}$ year, respectively, at $1 \mathrm{~km}$ away from the plant and 0.0048 , 0.035 , and $0.20 \mathrm{~g} / \mathrm{m}^{2}$ year, respectively, at $10 \mathrm{~km}$ away (Lu et al., 2010). Similarly, Li et al. (2012) investigated the metal pollution of the sediments from urban stream, estuary, and Jinzhou Bay. The estuary is the most polluted area, and contamination decreased with distance seaward of the river estuary, which indicated the impact of industrial activities on the abundance of heavy metals (Li et al., 2012).

\subsection{Situation of Shuangtaizi Estuary}

The Shuangtaizi Estuary is located in the downstream of Liaohe River, which is an important ecological and economic region in the northeast of the Bohai Sea. The wetland distributed around Shuangtaizi Estuary has been ranked as the largest bulrush wetland in the world, providing habitats for various marine organisms. However, the Shuangtaizi Estuary suffers from serious land-based sources of contamination. This estuary receives pollutants from industrial activities, non-point agriculture discharges, and urban activities. The Liao River Oilfield, which is the third largest oil field in China, mainly distributes around Panjin City around Shuangtaizi Estuary. Previous studies have investigated the metal pollution in this area (Li et al., 2015; Li et al., 2017; Yang et al., 2015), and one conclusion is that $\mathrm{Cd}$ and $\mathrm{Hg}$ were the dominant metal contaminations in terms of spatial distribution and 
Table 5

Pearson's correlation matrix for the heavy metals ( $\mathrm{Hg}, \mathrm{As}, \mathrm{Zn}, \mathrm{Cd}, \mathrm{Pb}, \mathrm{Cu}$ and $\mathrm{Cr}$ ), TOC and median diameter (Md).

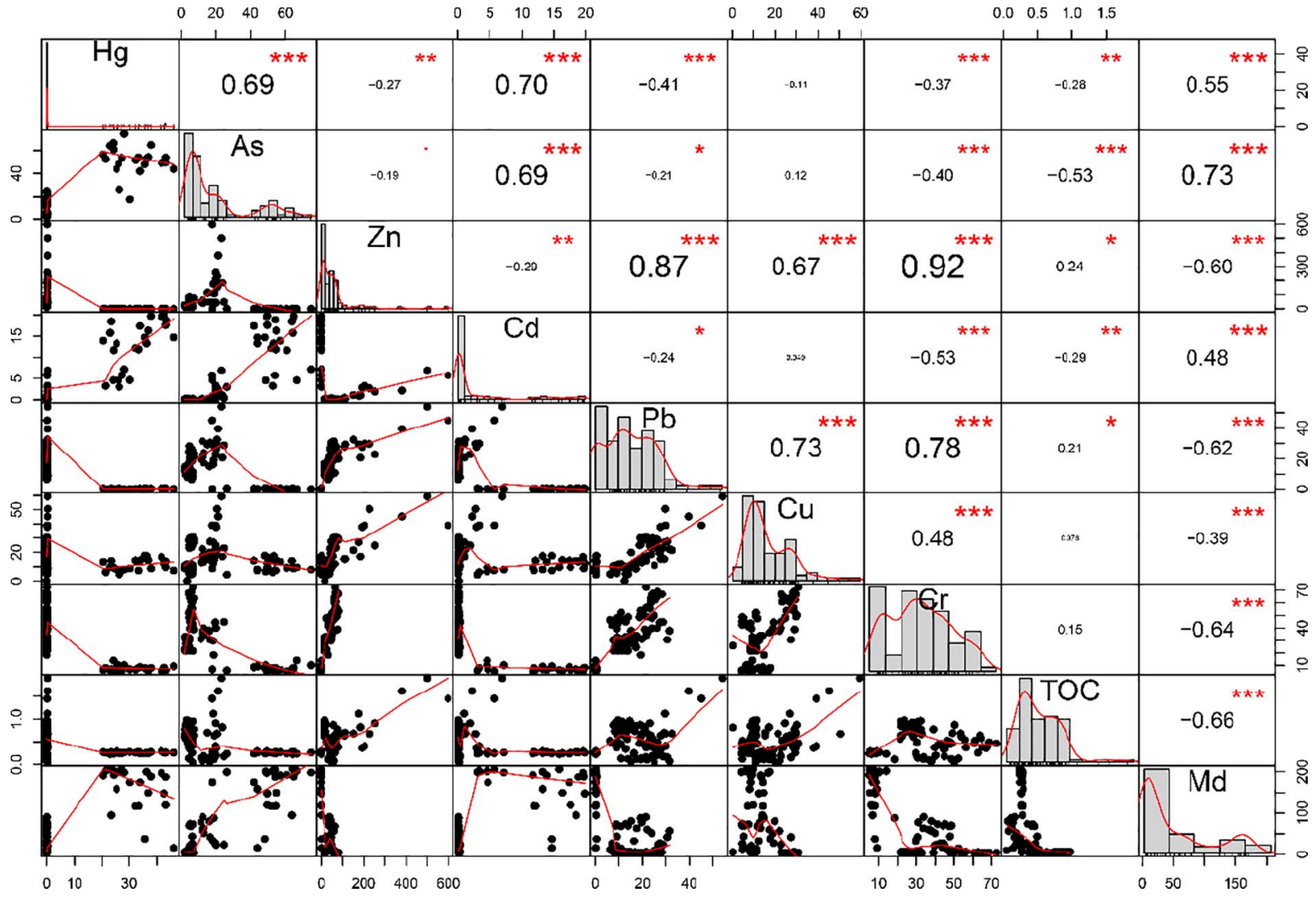

$* P<0.05, * * P<0.01$ and $* * * P<0.001$

potential ecological risk. The results of the present study were similar to those of previous studies, thereby demonstrating that $\mathrm{Cd}$ and $\mathrm{Hg}$ were significantly enriched in the sediment of the Shuangtaizi Estuary. Interestingly, a previous study was conducted on the Liaohe River protected area, which is located upstream of the Liaohe River (Ke et al., 2017). The study revealed that Cd had the highest contribution to metal pollution, with a high to very high potential risk; Cd and Zn originated from agriculture sources. Taken together, important strategies should be implemented to reduce the discharge of industrial wastewater. Controlling agricultural non-point source pollution is required to decrease the ecological risks associated with Cd pollution.

Table 6

Total variance explained and rotated component matrix of principal components analysis.

\begin{tabular}{lll}
\hline & RC1 & RC2 \\
\hline $\mathrm{As}$ & 0.89 & -0.35 \\
$\mathrm{Hg}$ & 0.84 & -0.44 \\
$\mathrm{Md}$ & 0.83 & -0.37 \\
$\mathrm{Cd}$ & 0.82 & -0.38 \\
$\mathrm{Cu}$ & 0.07 & 0.87 \\
$\mathrm{Zn}$ & -0.3 & 0.92 \\
$\mathrm{~Pb}$ & -0.44 & 0.83 \\
$\mathrm{Cr}$ & -0.46 & 0.82 \\
$\mathrm{TOC}$ & -0.78 & -0.29 \\
Eigenvalue & 5.85 & 1.78 \\
$\%$ total variance & 0.52 & 0.48 \\
$\%$ cumulative variance & 0.52 & 1.00 \\
\hline
\end{tabular}

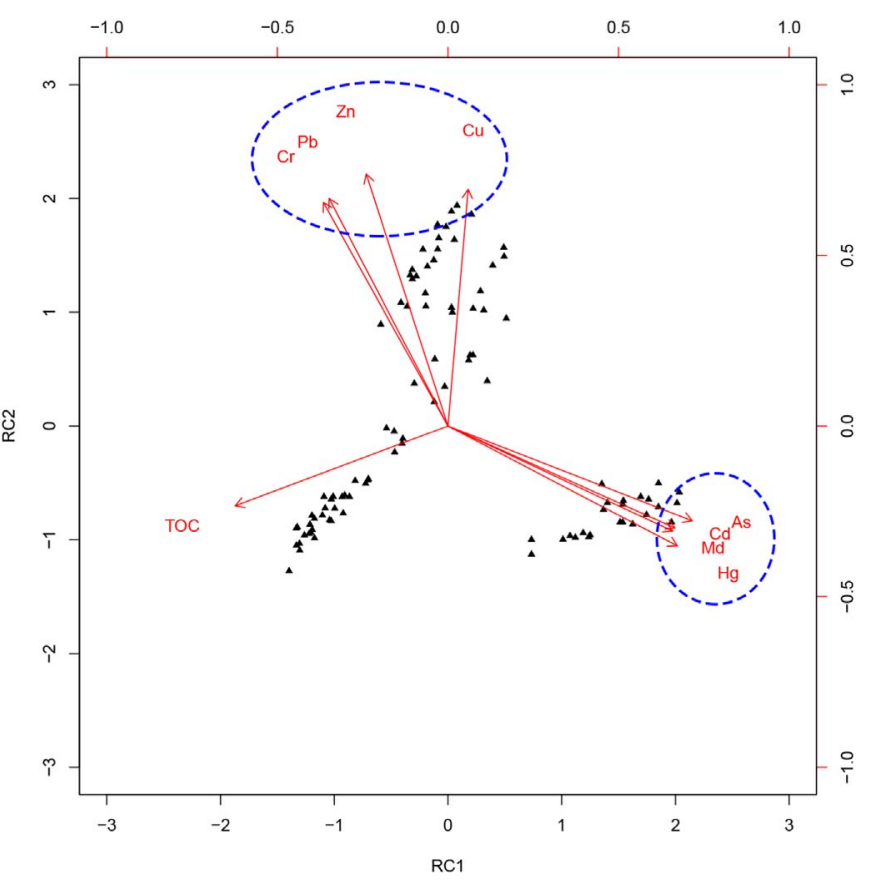

Fig. 5. Principal component loading of metal variables. 


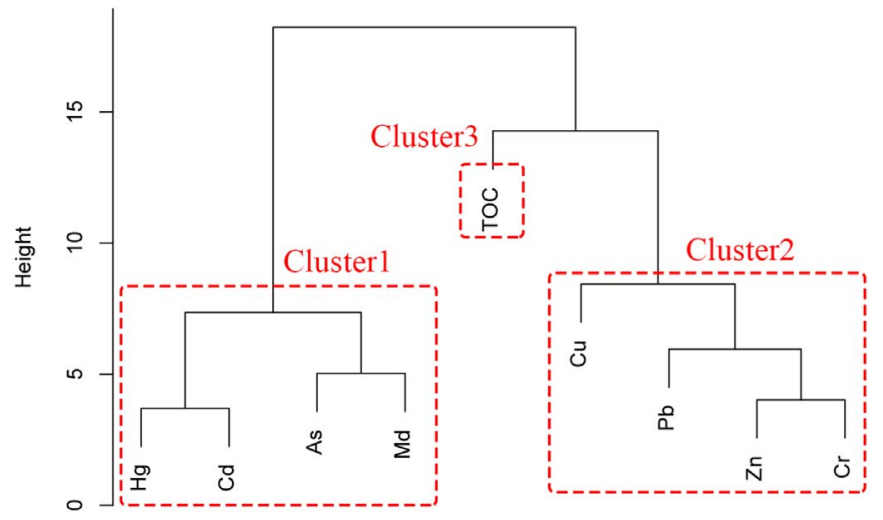

Fig. 6. Hierarchical clustering analysis among measured metals. Distance are based on the Euclidean distance single linkage method (nearest neighbor).

\subsection{Situation of Luanhekou Estuary}

The Luanhe River River is an important water resource of surrounding cities. With rapid industrialization and urbanization along the Luanhe River Basin in recent decades, large number of industrial, agricultural and domestic sewage have been discharged into the river. Accordingly, the total cumulative amounts of pollutants and heavy metals from Luanhe River discharged into the Bohai Sea reached $6.2 \times 10^{5} \mathrm{t}$ and $420 \mathrm{t}$ during 2003-2013 (DLRH, 2003-2013). In the present study, the heavy metal contents in the Luanhekou Estuary generally met the MSQ-1, and both $C F$ and $I_{\text {geo }}$ values showed weekly polluted by $\mathrm{Hg}$, $\mathrm{Cu}$ and As. Liu et al. (2016) studied the distributions, sources and ecological risk assessments of heavy metals in the sediments of Luanhe Estuary, and the results showed that metal contents were controlled by sediment environment, and high concentrations were observed in the samples with fine particles collected from the estuary and south part.

\subsection{Situation of Bohai Bay}

Surrounded by big cities and a highly industrialized region, Bohai Bay is facing a severe metal pollution problem. The bay is a typical semi-closed coastal area, with limited water exchange ability of the inner bay with the open ocean. The investigation data of metal pollution in the sediment of Bohai Bay from 1997 to 2007 indicated that the concentrations of $\mathrm{Cu}, \mathrm{Zn}, \mathrm{Pb}$, and $\mathrm{Cd}$ exceeded MSQ-1 in a few sampling sites at certain years, thereby suggesting anthropogenic influences on the sediment quality (Zhan et al., 2010). An investigation in May 2008 revealed that the $\mathrm{Cd}, \mathrm{Pb}, \mathrm{Zn}, \mathrm{Cu}$, and $\mathrm{Cr}$ contents at $98 \%, 95 \%, 86 \%$, $40 \%$, and $12 \%$, respectively, were within the range for MSQ-1 sediment identification in Bohai Bay. Hu et al. (2013) studied the potential contamination and environmental risks associated with metals, which indicated that the concentrations of $\mathrm{Cd}, \mathrm{Zn}, \mathrm{Cr}, \mathrm{Cu}$, and $\mathrm{Pb}$ in the Bohai Bay generally met MSQ-1. In the present study, the concentration of $\mathrm{Cu}$, $\mathrm{Zn}, \mathrm{Cr}, \mathrm{Hg}, \mathrm{Cd}, \mathrm{Pb}$, and As in all sampling sites in the sediments of Bohai Bay were all within the range of MSQ-1. This finding indicated that the overall sediment quality was in good condition, and Bohai Bay was not seriously polluted by heavy metals. Referring to a spatial distribution of metal concentrations in Bohai Bay, Gao and Chen (2012) clustered two main different sample groups based on the metal concentrations, with one group containing riverine regions that indicate heavy pollution and the other group of the remaining sites representing less polluted regions. No point source inputs from both fluvial transport and atmospheric deposition were important ways for sediment contamination to occur in Bohai Bay (Gao and Chen, 2012).

\subsection{Situation of Laizhou Bay}

Laizhou Bay is an important area for fish spawning, feeding, and cultivation. Nowadays, the bay has become a part of the Bohai economic rim and the Yellow River Economic Belt, one of the main parts of China's coastal economic belt. The rapid urbanization and industrialization have brought serious ecological damage to Laizhou Bay, and fishery resources are slowly declining. Metal contaminations of Laizhou Bay have been investigated over the past few years (Zhang et al., 2017; Zheng et al., 2015). A recent investigation in 2011 revealed an obvious pollution risk by $\mathrm{Cd}$, especially in sites near the river mouths and southwestern Laizhou Bay (Zhuang and Gao, 2014). In the present study, the Marine Sediment Quality of China showed that the sediment quality was in good condition, and $I_{g e o}$ analysis revealed that $\mathrm{Hg}$ caused moderate pollution.

\section{Conclusion}

The Bohai Sea is a semi-closed shallow marginal sea with special geographic and oceanographic characteristics. Given the rapid and intensive economic development of coastal regions around the Bohai Sea, metal pollution has become a nationwide public concern in recent years. This study demonstrated the spatial distribution and pollution status of heavy metals ( $\mathrm{Cu}, \mathrm{Cd}, \mathrm{As}, \mathrm{Pb}, \mathrm{Zn}, \mathrm{Cr}$, and $\mathrm{Hg}$ ) from the surface sediments in five coastal regions of the Bohai Sea. The concentrations of $\mathrm{Hg}$ and $\mathrm{Cd}$ were considerably higher than the average upper crust value and presented high potential ecological risk and considerable potential ecological risk, respectively. Spatial distribution patterns showed that the sedimentary environments of coastal Bohai were in good condition, except Jinzhou Bay, according to the Marine Sediment Quality of China. The overall environment quality of the coastal Bohai Sea does not seem to pose a very serious threat in terms of metal pollution, which demonstrates that protective actions in the Bohai Sea have had positive effects. This environment quality evaluation will serve as a basis for monitoring and protecting the Bohai Sea.

\section{Acknowledgments}

This study was supported by Grants from National Natural Science Foundation of China (31572595).

\section{References}

Cheng, S., 2003. Heavy metal pollution in China: origin, pattern and control. Environ. Sci. Pollut. Res. 10, 192-198.

DLRH, 2003-2013. Department of Land and Resource (Oceanic Administration) of Hebei Province. Marine Environment Condition Bulletin of Hebei Province.

Eggleton, J., Thomas, K.V., 2004. A review of factors affecting the release and bioavailability of contaminants during sediment disturbance events. Environ. Int. 30 (7), 973-980.

Fan, W.H., Zhang, B., Zhang, R., Deng, B.S., 2008. Speciation characteristics and potential ecological risk of heavy metals in surface sediments of Jinzhou Bay. Mar. Environ. Sci. 27 (1), 54-58 (Chinese edition with English abstract).

Feng, H., Han, X.F., Zhang, W.G., Yu, L.Z., 2004. A preliminary study of heavy metal contamination in Yangtze River intertidal zone due to urbanization. Mar. Pollut. Bull. 49 (11-12), 910-915.

Förstner, U., Wittmann, G.T., 2012. Metal Pollution in the Aquatic Environment. Springer Science \& Business Media.

Furness, R.W., 2018. Heavy Metals in the Marine Environment. CRC press.

Gao, X.L., Chen, C.T.A., 2012. Heavy metal pollution status in surface sediments of the coastal Bohai Bay. Water Res. 46, 1901-1911.

Gao, S., Luo, T.C., Zhang, B.R., Zhang, H.F., Han, Y.W., Zhao, Z.D., Hu, Y.K., 1998. Chemical composition of the continental crust as revealed by studies in East China. Geochim. Cosmochim. Acta 62 (11), 1959-1975.

Gao, X.L., Zhou, F.X., Chen, C.T.A., 2014. Pollution status of the Bohai Sea: an overview of the environmental quality assessment related trace metals. Environ. Int. 62, 12-30.

Hakanson, L., 1980. An ecological risk index for aquatic pollution control. a sedimentological approach. Water Res. 8, 975-1001.

Hu, B.Q., Li, G.G., Li, J., Bi, J.Q., Zhao, J.T., Bu, R.Y., 2013. Spatial distribution and ecotoxicological risk assessment of heavy metals in surface sediments of the southern Bohai Bay, China. Environ. Sci. Pollut. Res. 20, 4099-4110.

Ip, C.C.M., Li, X.-D., Zhang, G., Wai, O.W.H., Li, Y.-S., 2007. Trace metal distribution in 
sediments of the Pearl River Estuary and the surrounding coastal area, South China. Environ. Pollut. 147, 311-323.

Jin, X.S., 2004. Long-term changes in fish community structure in the Bohai Sea, China. Estuar. Coast. Shelf Sci. 59, 163-171.

Ke, X., Gui, S.F., Huang, H., Zhang, H.J., Wang, C.Y., Guo, W., 2017. Ecological risk assessment and source identification for heavy metals in surface sediment from the Liaohe River protected area, China. Chemosphere 175, 473-481.

Li, X.Y., Liu, L.J., Wang, Y.G., Luo, G.P., Chen, X., Yang, X.L., Gao, B., He, X.Y., 2012. Integrated assessment of heavy metal contamination in sediments from a coastal industrial basin, NE China. PLoS One 7 (6), e39690.

Li, C., Song, C.W., Yin, Y.Y., Sun, M.H., Tao, P., Shao, M.H., 2015. Spatial distribution and risk assessment of heavy metals in sediments of Shuangtaizi estuary, China. Mar. Pollut. Bull. 98 (1-2), 358-364.

Li, H.J., Ye, S., Ye, J.Q., Fan, J.F., Gao, M.L., Guo, H., 2017. Baseline survey of sediments and marine organisms in Liaohe Estuary: heavy metals, polychlorinated biphenyls and organochlorine pesticides. Mar. Pollut. Bull. 114, 555-563.

Liang, L.N., He, B., Jiang, G.B., Chen, D.Y., Yao, Z.W., 2004. Evaluation of mollusks as biomonitors to investigate heavy metal contaminations along the Chinese Bohai Sea. Sci. Total Environ. 324, 105-113.

Liu, J.Q., Yin, P., Chen, B., Gao, F., Song, H.Y., Li, M.N., 2016. Distribution and contamination assessment of heavy metals in surface sediments of the Luanhe River Estuary, northwest of the Bohai Sea. Mar. Pollut. Bull. 109, 633-639.

Long, E.R., Field, L.J., MacDonald, D.D., 1998. Predicting toxicity in marine sediments with numerical sediment quality guidelines. Environ. Toxicol. Chem. 17 (4), 714-727.

Loska, K., Cebula, J., Pelczar, J., Wiechuła, D., Kwapuliński, J., 1997. Use of enrichment, and contamination factors together with geoaccumulation indexes to evaluate the content of $\mathrm{Cd}, \mathrm{Cu}$, and Ni in the Rybnik water reservoir in Poland. Water Air Soil Pollut. 93 (1-4), 347-365.

Lu, C.A., Zhang, J.F., Jiang, H.M., Yang, J.C., Zhang, J.T., Wang, J.Z., Shan, H.X., 2010. Assessment of soil contamination with $\mathrm{Cd}, \mathrm{Pb}$ and $\mathrm{Zn}$ and source identification in the area around the Huludao Zinc Plant. J. Hazard. Mater. 182 (1-3), 743-748.

Macdonald, D.D., Carr, R.S., Calder, F.D., Long, E.R., Ingersoll, C.G., 1996. Development and evaluation of sediment quality guidelines for Florida coastal waters. Ecotoxicology 5 (4), 253-278.

Muller, G., 1969. Index of geoaccumulation in the sediments of the Rhine River. Geo J. 2, 109-118.

Pan, K., Wang, W.X., 2012. Trace metal contamination in estuarine and coastal environments in China. Sci. Total Environ. 421, 3-16.

Qiao, Y.M., Yang, Y., Gu, J.G., Zhao, J.G., 2013. Distribution and geochemical speciation of heavy metals in sediments from coastal area suffered rapid urbanization, a case study of Shantou Bay, China. Mar. Pollut. Bull. 68 (1-2), 140-146.
Revelle, W., 2017. psych: Procedures for Personality and Psychological Research. Northwestern University, Evanston, Illinois, USA.

SEPA (State Environmental Protection Administration of China), 2002. Marine Sediment Quality (GB 18668-2002). Standards Press of China, Beijing (In Chinese).

Wang, C.Y., Wang, X.L., 2007. Spatial distribution of dissolved Pb, Hg, Cd, Cu and As in the Bohai Sea. J. Environ. Sci. 19, 1061-1066.

Wang, S.F., Jia, Y.F., Wang, S.Y., Wang, X., Wang, H., Zhao, Z.X., Liu, B.Z., 2010. Fractionation of heavy metals in shallow marine sediments from Jinzhou Bay, China. J. Environ. Sci. 22, 23-31.

Wang, S.L., Xu, X.R., Sun, Y.X., Liu, J.L., Li, H.B., 2013. Heavy metal pollution in coastal areas of South China: a review. Mar. Pollut. Bull. 76 (1), 7-15.

Ward, J., 1963. Hierarchical grouping to optimize an objective function. J. Am. Stat. Assoc. 58, 236-244.

Xu, S.S., Song, J.M., Duan, L.Q., Wu, X.D., Xu, Y.Y., 2010. Functional groups of fish assemblages and their major species in the Bohai Sea. Mar. Sci. 34, 59-65 (Chinese edition with English abstract).

Xu, X.D., Cao, Z.M., Zhang, Z.X., Li, R.H., Hu, B.Q., 2016. Spatial distribution and pollution assessment of heavy metals in the surface sediments of the Bohai and Yellow Seas. Mar. Pollut. Bull. 110 (1), 596-602.

Yang, X.L., Yuan, X.T., Zhang, A.G., Mao, Y.Z., Li, Q., Zong, H.M., Wang, L.J., Li, X.D., 2015. Spatial distribution and sources of heavy metals and petroleum hydrocarbon in the sand flats of Shuangtaizi Estuary, Bohai Sea of China. Mar. Pollut. Bull. 95 (1), 503-512.

Zhan, S.F., Peng, S.T., Liu, C.G., Chang, Q., Xu, J., 2010. Spatial and temporal variations of heavy metals in surface sediments in Bohai Bay, North China. Bull. Environ. Contam. Toxicol. 84, 482-487.

Zhang, G.S., Liu, D.Y., Wu, H.F., Chen, L.L., Han, Q.X., 2012. Heavy metal contamination in the marine organisms in Yantai coast, northern Yellow Sea of China. Ecotoxicology 21, 1726-1733.

Zhang, P., Hu, R.J., Zhu, L.H., Wang, P., Yin, D.X., Zhang, L.J., 2017. Distributions and contamination assessment of heavy metals in the surface sediments of western laizhou bay: implications for the sources and influencing factors. Mar. Pollut. Bull. 119, 429-438.

Zheng, N.A., Wang, Q., Liang, Z., Zheng, D., 2008. Characterization of heavy metal concentrations in the sediments of three freshwater rivers in Huludao City, Northeast China. Environ. Pollut. 154 (1), 135-142.

Zheng, Y.M., Gao, M.S., Liu, S., Zhao, J.M., Guo, F., Wang, C.M., 2015. Distribution patterns and ecological assessment on heavy metals in the surface sediments of Laizhou Bay. Mar. Environ. Sci. 34, 354-360 (Chinese edition with English abstract).

Zhuang, W., Gao, X.L., 2014. Integrated assessment of heavy metal pollution in the surface sediments of the Laizhou Bay and the coastal waters of the Zhangzi Island, China: comparison among typical marine sediment quality indices. PLoS One 9, e94145. 